Ann. Biol. anim. Bioch. Biophys., 1978, 18 (2 B), 359-365.

\title{
Morphological and biochemical aspects of mammalian meiosis
}

\author{
by Ann C. CHANDLEY
}

MRC Clinical and Population Cytogenetics Unif,

Western General Hospital, Crewe Road, Edinburgh, Scotland, U. K.

\begin{abstract}
Summary. The principal processes of meiosis, pairing, crossing-over and reductional segregation of chromosomes make up a spatially well-ordered and temporally wellregulated succession of events. In the male mammal, meiosis is an integral part of spermatogenesis. While the cytological aspects of meiosis have been the focus of study for investigators over many years. the biochemical properties of mammalian meiotic cells have only recently begun to be elucidated. Studies have shown that a series of key events takes place in prophase spermatocytes of the mouse. These are virtually identical to biochemical events previously reported for microsporocytes of Lilium, a much more thoroughly investigated organism. They include a small semi-conservative synthesis of DNA during the early prophase and single strand nicking of DNA coordinated with repair replication of DNA at pachytene. Early prophase DNA synthesis has been assigned a role in synapsis ; pachytene DNA synthesis a role in crossing-over. Little can be said at the present time about the genetic control of meiosis in mammals. However, studies in Drosophila provide valuable information on the consequences of mutations that interrupt the normal sequence of meiotic events.
\end{abstract}

\section{Introduction.}

Our current knowledge of the events taking place at meiosis comes principally from genetic data on the transmission of traits and from cytological studies on pairing and chiasma formation. Additional pointers to possible mechanisms are provided by studies on the fine structure of the synaptonemal complex, the effects of external agents on the three principle meiotic events, recombination, chiasma formation and disjunction, and autoradiographic studies into the metabolic activities of various cell stages.

The simplest picture of meiosis that may be drawn from these disciplines is that chromosomes synapse during the zygotene stage and undergo crossing-over at pachytene. Though highly attractive in its apparent simplicity, this picture has been challenged by a number of investigators. However, recent biochemical data now provide an appreciable body of circumstantial evidence which supports the conclusions drawn from the genetic and cytological studies (Stern and Hotta, 1974 ; Hotta ef al., 1977a).

Let us first consider the cytological framework. In all mammalian species, the germ-line is derived from somatic cells and every meiotic cell is the product of a mitotic division. The conversion from mitosis to meiosis is not achieved abruptly, but 
is approached over several cell generations. The first distinguishable difference between the meiotic and mitotic cycles is in the duration of the S-phase. In many species, the spermatocyte S-period is significantly longer than the spermatogonial Speriods. In the mouse for example, Monesi (1962) has estimated the S-phase of the preleptotene spermatocyle to be $14 \mathrm{hrs}$, and that of the Type A spermatogonium to be only 7-8 hrs. This extended period of chromosome replication may be related to the preparation of the meiotic chromatin for participation in the later events of meiotic prophase.

The first functionally significant and microscopically observable event in meiotic prophase is the synapsis of chromosomes. The pre-synaptic events begin at leptotene, when the lateral elements of the synaptonemal complex first appear (von Wettstein, 1977). At zygotene, the chromosomes are already considerably condensed, and although no precise figure is available, it has been estimated that probably less than 1 p. 100 of the DNA could be located at the periphery of the chromosomes and thus available to form matching sites for synaptic alignment (Stern and Hotta, 1974). Such DNA-DNA matching between sites is believed to be atransient event, the matched sites being immediately stabilized by the formation of the synaptonemal complex. The complex is present throughout pachytene as a continuous tripartite structure between the two homologous chromosomes in a bivalent. After pachytene, the chromosomes condense rapidly, the synaptonemal complex is shed, except at places where the homologous chromosomes are held together by chiasmata, and the cell passes through diplotene and diakinesis. These stages complete the progress through meiotic prophase and the 1 st and 2 nd meiotic divisions follow, thus establishing haploidy.

Over the past 15 years or so, detailed biochemical studies of the events taking place at meiotic prophase have been undertaken by Hotta and Stern working in the University of California at San Diego. Lilium was the organism chosen for their studies by virtue of three great advantages which this species holds over any mammalian species.

First of all, the prophase stages are of relatively long duration and thus clearly separable. Secondly, flower bud length can be used as an easy index of developmental stage in the pollen mother cell. Thirdly, pollen mother cells can be successfully cultured in vitro, thus enabling labelling and treatment of meiocytes to be efficiently carried out under controlled laboratory conditions.

The biochemical studies of Hotta and Stern have shown many interesting features of the processes taking place at meiotic prophase and have revealed a remarkable degree of consistency with the information provided by genetics and cytology.

First of all, they have shown that in addition to the pre-meiotic S-phase, two further distinct intervals of DNA synthesis occur, one during zygotene when chromosomes are pairing and the other during pachytene when paired chromosomes are presumed to be undergoing crossing-over.

\section{Zygotene synthesis}

(a) Zygotene synthesis represents about 0.3 p. 100 of the nuclear genome which is delayed in replication from the pre-meiotic S-period; chromosome replication during the pre-meiotic S-period is therefore only 99.7 p. 100 complete. 
(b) Autoradiographic studies show that the sites of Z-DNA synthesis are randomly distributed over the chromosomes when these are viewed at diakinesis.

(c) Arrest of Z-DNA synthesis at the beginning of zygotene by the DNA synthesis inhibitor deoxyadenosine, prevents formation of the synaptonemal complex and thus it is concluded that Z-DNA has a functional role in chromosome pairing.

(d) Inhibition later in zygotene produces fragmented chromosomes at diakinesis resulting from the production of unreplicated gaps in the DNA.

(e) Chemical analysis shows Z-DNA to be G-C rich and to consist entirely of unique sequences.

(f) Persistent discontinuities occur in the Z-DNA which are not ligated until the chromosomes disjoin at anaphase 1. The function of such discontinuities is not yet known.

Zygotene DNA is considered by Stern and Hotta (1974) to be an attractive candidate as a synaptic agent, since its delayed replication coincides with, and appears to be essential to pairing. They believe that since pairing is such a precise process, matching of the partly condensed zygotene chromosomes must be achieved by relatively short stretches of DNA distributed along the length of each homologue and exposed for interaction - the so-called "synaptic sites ». Inhibition of Z-DNA synthesis will thus prevent the formation of these sites and inhibit the ultimate formation of the synaptonemal complex.

\section{Pachytene synthesis}

(a) Pachytene DNA synthesis, or «P »-DNA synthesis, appears to occur at about one third the level of zygotene synthesis.

(b) Treatment with hydroxurea gives strong inhibition at S-phase and zygotene, but little response at pachytene, thus indicating a « repair » type of replication.

(c) The distribution of repaired sequences shows them to be preferentially located in regions of moderately repeated DNA, the length of the repeats being estimated as 100-200 bases.

(d) Evidence that pachytene DNA synthesis has a functional role in crossing-over comes from studies with an achiasmatic hybrid of Lilium known as «Black Beauty 》, which shows a very low level of such synthesis.

In addition to demonstrating that there are these two distinct periods of DNA synthesis at the meiotic prophase in Lilium, Hotta and Stern discovered three other features which contribute to our understanding of the processes operating at zygotene and pachytene in pairing and crossing-over.

They postulated (Howell and Stern, 1971) that the mechanism for genetic recombination in the eukaryotic nucleus would parallel the breakage and reunion events found in prokaryotes. Thus, they expected to find evidence at pachytene for scission of parental DNA strands, molecular hybridisation by base-pairing of complementary DNA strands and rejoining (Meselson and Weigle, 1961). In fact, their studies in Lilium gave results which were entirely compatible with these predictions. Peak levels of endonuclease and ligase activities were identified at late zygotene to pachytene, these 
being the enzymes required to effect breakage and rejoining of DNA strands for recombination. Secondly, peak levels of a reassociation protein which could bind to singlestranded DNA and facilitate its renaturation were found at zygotene and pachytene. This they believed was essential to both pairing and crossing-over. It was not found in somatic cells or in cells at the pre-meiotic interphase. Thirdly, they found clear evidence of single strand nicks and gaps in the DNA at pachytene which they believed represented the scissions required for crossing-over. In situations where crossing-over failed as in the achiasmatic hybrid "Black Beauty 》, nicking was not found (Hotta and Stern, 1974). In yeast, a similar pattern of nicking has been observed (Jacobsen ef al., 1975). Now, although all of these findings do not constitute proof that crossingover occurs at pachytene, they do provide very strong circumstantial evidence.

\section{Biochemical studies in the mouse}

In spite of the obvious need to understand how mammalian meiotic cells organize their DNA metabolism to effect crossing-over, the processes remain obscure mainly because of the difficulties in obtaining sufficient quantities of synchronized meiotic cells for biochemical analysis. Unlike the lily in which meiocytes develop synchronously, and in which easily measured bud lengths can be used to predict meiotic stage, the meiotic cells in a normal mammalian testicular suspension span all stages of development. A major step forward in making biochemical studies of meiosis a feasible proposition in mammals was the elaboration of a procedure for fractionating rodent spermatocytes according to developmental stage (Miller and Phillips, 1969). The socalled «Staput " method of cell separation at unit gravity allows collection of purified fractions of individual cell types. A cell suspension from the mouse testis, prepared by collagenase and trypsin digestion (Chandley ef al., 1977) is loaded on a bovine serum albumin gradient. The cells are allowed, over a $4 \mathrm{hr}$ period to sediment through the gradient at $4{ }^{\circ} \mathrm{C}$, and are thereby separated according to size. Large cells such as pachytene spermatocytes sink more quickly through the gradient than the smaller early prophase stages and spermatids, and bands of purified cell fractions are thus obtained. Using this procedure, we have obtained an 85 p. 100 purity of pachytene spermatocytes which has enabled us to repeat some of the experiments carried out on pachytene cells of the lily.

Our results (Hotta et al., $1977 a$ and $b$ ) show that the mouse and lily share several common features :

(a) single stranded nicks occur in mouse DNA at pachytene with a spacing very similar to that found in Lilium ;

(b) endogenous repair synthesis occurs in both strands of the DNA at pachytene ;

(c) the repair occurs preferentially in regions of moderately repeated DNA;

(d) a reassociation protein which facilitates DNA reannealing occurs at prophase and reaches a peak level in zygotene and pachytene.

The evidence, limited though it is, points unambiguosly to the conclusion that in organisms as diverse as lily and the mouse, metabolic events associated with crossingover share a common pattern. The preferential and programmed nicking of DNA in regions of moderate repeats, the similarity in spacing between nicked sites, and 
the temporal correlation between endogenous repair synthesis and cytological stage, are impressive examples of a conserved biochemical programme for meiosis which tempts us to suggest that there may be a universal mechanism for meiosis in all eukaryotic organisms (Hotta ef al. 1977a, b).

\section{The action of meiotic mutants}

Just as lily is well suited to an investigation of meiosis at the molecular level, so Drosophila is the organism par excellence for genetic investigations. Techniques are now available in Drosophila for screening the entire genetic complement for mutations of genes whose activity is essential for the orderly progression of meiosis (Baker et al., 1976).

Most meiotic mutants in Drosophila are sex specific and since it is only in the female that recombination and synaptonemal complex formation occur, it is female meiotic mutants which have been the most thoroughly investigated. The mutants fall into two classes - « recombination defective » and « disjunction defective » and, depending on their time of action, three sensitive stages have been defined (Lindsley and Sandler, 1977).

\section{Pre-pachytene mutants.}

The mutants « $3 G$ » and «mei-W68 » are examples of mutants which totally eliminate genetic recombination, and prevent formation of the synaptonemal complex between homologous chromosomes. Females homozygous for either of these mutants produce a very high frequency of non-disjunction at the first meiotic division. " ord " is a mutant which reduces recombination to about 10 p. 100 its normal level and here, the synaptonemal complex is incomplete and abnormally formed (Carpenter, unpublished).

\section{Pachytene mutants.}

Mutants which reduce recombination but which have no obvious effects on the synaptonemal complex include «mei-9 », « mei-41», « mei-218» and « mei-282 ». All have been shown to be defective in the repair of UV damaged DNA, implying that the same gene functions that in meiosis govern recombination, are required in mitosis for the repair of DNA damage. Reconstructions of pachytene nuclei from females homozygous for « mei- 41 » and « mei-218》 indicate that both mutants result in an inaccurate assembly and abnormal distribution of recombination nodules along the chromosome arms (Carpenter, unpublished).

\section{Post-pachytene mutants.}

A meiotic mutant that leads to irregular disjunction in association with normal levels of recombination is claret non-disjunctional «cand ». Females homozygous for this gene show increased rates of non-disjunction at the first meiotic division. There is also substantial meiotic chromosome loss at both meiotic divisions. Another post-pachytene mutant is «mei-S332 » which causes an increased level of nondisjunction of all chromosomes at the second meiotic division. It also effects males, 
unlike most of the other mutants described. Finally, the $X$-linked « eq » and the 2nd chromosome mutant «mei-G87» increase non-disjunction at the second meiotic division but only in the chromosomes that bear the mutani genes.

As well as in Drosophila, meiotic mutants have been described in fungi, other lower eukaryotes and in higher plants, but no proven examples have been exhibited in man or other mammals (Baker et al., 1976). There are some kinds of suggestive evidence such as the non-random clustering of chromosomal abnormalities within human kinships and instances of meiotic anomalies in sterile males with some evidence that these represent meiotic mutants segregating in families. The latter type of abnormality represents probably the most likely example of a meiotic muiant in man. The picture at meiosis in the supposed homozygous recessive male usually shows a series of associated features, namely an unusually low chiasma count at diakinesis, high numbers of univalent chromosomes at this stage, and maturation arrest resulting in azoospermia or severe oligospermia (Pearson et al., 1970). Abnormalities in pairing at pachytene and in the formation of the synaptonemal complex are also sometimes observed (Hultén ef al., 1974). Genetic causation in the various cases reported in the literafure is suggested by the fact that two of the azoospermic men were from consanguineous marriages and another had a childless sister. The observations suggest that the condition is due to a recessive meiotic mutant gene analogous to others described in lower organisms. However our knowledge of meiotic mutants in mammals remains very incomplete compared to the wealth of information available in Drosophila.

$27 \mathrm{e}$ Congrès international des Sciences physiologiques,

Symposium « Germ and somatic cell inferaction 》 Paris, 21-23 juillet 1977.

Résumé. Les principales étapes de la méiose, appariement, «crossing-over 》 et division réductionnelle des chromosomes, forment une succession d'événements bien ordonnés dans l'espace et bien régulés dans le temps. Chez le mammifère mâle, la méiose est une part intégrante de la spermatogenèse. Les aspects cytologiques de la méiose ont constitué pendant de nombreuses années le principal sujet d'étude des chercheurs, et ce n'esł que récemment que les propriétés biochimiques des cellules méiotiques ont commencé à être élucidées. Les recherches montrent qu'une série d'événements-clé se produisent dans les spermatocytes en prophase chez la souris, événements pratiquement identiques à ceux décrits précédemment dans les microsporocytes de Lilium, espèce éłudiée beaucoup plus minutieusement. Ces événements biochimiques comprennent une petite synthèse d'ADN semi-conservative au stade zygotène ef des coupures monocaténaires de l'ADN associées à une replication réparative de l'ADN au pachytène. La synthèse de l'ADN au début de la prophase jouerait un rôle dans l'appariement des chromosomes, celle qui se produit au pachytène interviendrait dans le crossing-over. On sait actuellement peu de choses sur le contrôle génétique de la méiose chez les mammifères. Cependant, les recherches réalisées chez la drosophile donnent des informations intéressantes sur les conséquences des mutations qui interrompent la séquence normale des événements dans la méiose.

\section{References}

BAKER B. S., CARPENTER A. T. C., ESPOSITO M. S., ESPOSITO R. E., SANDLER L., 1976. The genetic control of meiosis. Ann. Rev. Genet., 10, 53-134.

CHANDLEY A. C., HOTTA Y., STERN H., 1977. Biochemical analysis of meiosis in the male mouse. I. Separation and DNA labelling of specific spermatogenic sta ges. Chromosoma, 62, 243-253. 
HOTTA Y., STERN H., 1974. DNA scission and repair during pachytene in Lilium. Chromosoma, 46, 279-296.

HOTTA Y., CHANDLEY A. C., STERN H., 1977a. Biochemical analysis of meiosis in the male mouse. II. DNA metabolism at pachytene. Chromosoma, 62, 255-268.

HOTTA Y., CHANDLEY A. C., STERN H., 1977b. Organization for crossing-over in Lily and mouse. Nature 269, 240-242.

HOWELL S., STERN H., 1971. The appearance of DNA breakage and repair activities in the synchronous meiotic cycle of Lilium. J. mol. Biol., 55, 357-378.

HULTÉN M., SOLARI A. J., SKAKKEBAEK N. E., 1974. Abnormal synaptonemal complex in an oligoachiasmatic man with spermatogenic arrest. Hereditas, 78, 105-116.

JACOBSEN G. K., PINON R., ESPOSITO R. E., EXPOSITO M. S., 1975. Single strand scissions of chromosomal DNA during commitment to recombination at meiosis. Proc. nat. Acad. Sci., Wosh., 72, 1887-1891.

LINDSLEY D. L., SANDLER L., 1977. The genetic analysis of meiosis in female Drosophila melanogasfer. Phil. Trans. roy. Soc. Lond. B., 277, 295-312.

MESELSON M., WEIGLE J. J., 1961. Chromosome breakage accompanying genetic recombination bacteriophage. Proc. nat. Acad. Sci., Wash., 47, 857-868.

MILLER R. G., PHILLIPS R. A., 1969. Separation of cells by velocity sedimentation. J. cell. Physiol., 73, 197-201.

MONESI V., 1962. Autoradiographic study of DNA synthesis and the cell cycle in spermatogonia and spermatocytes of mouse testis using tritiated thymidine. J. Cell Biol., 14, 1-18.

PEARSON P. L., ELLIS J. D., EVANS H. J., 1970. A gross reduction in chiasma formation during meiotic prophase and a defective DNA repair mechanism associated with a case of human male infertility. Cytogenefics, 9, 460-467.

STERN H., HOTTA Y., 1974. Biochemical controls of meiosis. Ann. Rev. Genet., 7, 37-66.

VON WETTSTEIN D., 1977. The assembly of the synaptonemal complex. Phil. Trans. roy. Soc. Lond. B., 277, 235-243. 